Thorax, 1979, 34, 621-628

\title{
Cellular aggregation and trauma in cardiotomy suction systems
}

\author{
G WRIGHT AND J M SANDERSON
}

From the WE Dunn Unit of Cardiology, Keele University, Keele, and the North Staffordshire Royal Infirmary, Stafford, Staffordshire, UK

ABSTRACT Experiments in dogs showed that the high levels of cellular aggregation and trauma caused by cardiotomy suction can be considerably reduced by the avoidance of air aspiration. A hypothesis is proposed to explain this on the basis of shear stresses in the inlet cannula. Roller pump suction was also found to be slightly more traumatic than vacuum suction, but contact of the blood with the pericardium had no effect so long as the pericardium and epicardium had been previously washed with saline.

Examination of the factors responsible for cellular aggregation and trauma during extracorporeal circulation for open heart surgery showed that these effects could be largely avoided by simple technical precautions, but that further studies of the cardiotomy suction system were required (Wright, 1976, 1977). Other investigators have reported that cardiotomy suction is responsible for severe haemolysis (Morris et al, 1965; Wells et al, 1968), particulate embolisation (Page et al, 1974; Solis et al, 1974, 1975), the formation of fat globules (Caguin and Carter, 1963; Wright et al, 1963; Evans and Wellington, 1964), and the generation of gas microbubbles (Loop et al, 1976; Furness, 1977). Microemboli pumped into the patients' systemic arteries are thought to cause embolic tissue damage, but this can be reduced by microfiltration of the cardiotomy suction blood (Hill et al, 1970; Osborn et al, 1970; Katsumoto et al, 1973; Skagseth et al, 1974).

There are several possible explanations for the cell trauma in the cardiotomy suction system. Morris et al (1965) claimed that the high levels of plasma haemoglobin in cardiotomy suction blood were due to contact of the blood with the pericardium. Rygg (1973), however, found that the haemolysis could be reduced by the reduction of air aspiration and by the use of a low pressure suction system (vacuum) instead of a roller pump. Possibly the low pressures generated in the suction system could be responsible for the haemolysis, but this seems unlikely since Wielogorski et al (1975) showed that haemolysis was only minimal so long as the absolute pressure exceeded $150 \mathrm{mmHg}$.

Thus the hypotheses to be tested are that cardiotomy suction causes cellular aggregation and trauma; that the aggregates can be removed by filtration; that this will reduce tissue damage; that contact of the blood with the pericardium causes haemolysis; that vacuum suction causes less haemolysis than roller pump suction; and that the haemolysis can be reduced by the avoidance of air aspiration.

\section{Materials and methods}

For in-vivo experiments 36 beagle dogs $10.4-27.6 \mathrm{~kg}$ (mean 13.4) body weight were anaesthetised by an intravenous injection of $0.4-0.5 \mathrm{~g}$ thiopentone sodium (Intraval), intubated, and provided with intermittent positive-pressure ventilation by an East Radcliffe ventilator delivering equal flow rates of oxygen and nitrous oxide in a semi-closed circuit. Anaesthesia was maintained for about five hours by the continuous intravenous infusion at $1 \mathrm{ml} / \mathrm{min}$ of $0.9 \%$ sodium chloride containing $0.4 \mathrm{~g}$ Intraval per $100 \mathrm{ml}$.

A mid-line thoracotomy was performed, and the pericardium was incised so that the cut edges could be sutured to the thoracic rim to form a pericardial well. Sodium heparin, $300 \mathrm{IU} / \mathrm{kg}$ body weight was given via a femoral vein, and a $6 \mathrm{~mm}$ or $9 \mathrm{~mm}$ internal diameter Polystan polyvinyl chloride catheter was inserted into the left atrium via the atrial appendage.

The extracorporeal circuit is shown diagrammatically in figs $1 \mathrm{a}$ and $\mathrm{b}$. The circuit consisted of a Travenol SM0305 rigid cardiotomy reservoir, a BioMed Engineering torpedo type stainless steel heat exchanger, and a Travenol 6LF pump set. Roller pump suction was provided by a Sarns roller pump, and vacuum suction was obtained by an Associated Electrical Industries exhauster/compressor coupled 

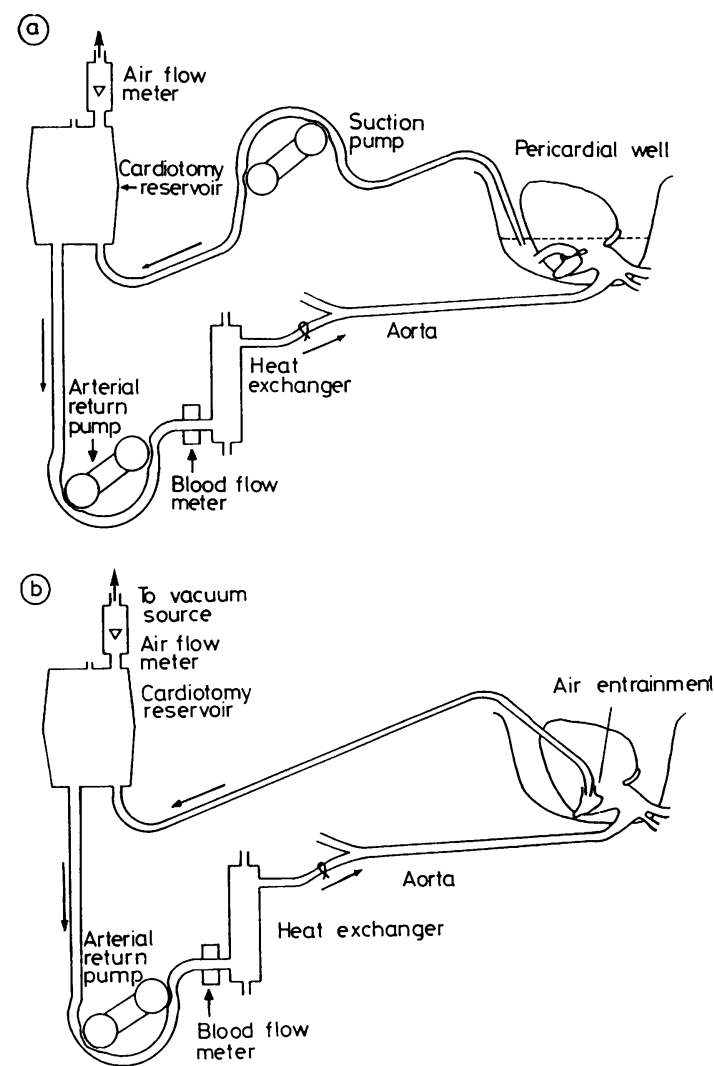

Fig 1 (a) Experimental circuit showing direct collection of blood from left atrium using vacuum suction system.

(b) Experimental circuit showing aspiration of a bloodlair mixture from pericardial well using roller pump system.

to the cardiotomy reservoir. Tubing lengths were standard for all experiments so that the $4 \mathrm{~mm}$ internal diameter stainless steel cannula (within the left atrial catheter or in the pericardial well) was connected to the cardiotomy reservoir by $1 \mathrm{~m}$ of $6 \mathrm{~mm}$ internal diameter polyvinyl chloride tubing. The circuit was primed with $500 \mathrm{ml}$ Ringer-lactate solution, $5 \mathrm{ml} 8.4 \%$ sodium bicarbonate, and $100 \mathrm{IU} /$ $\mathrm{kg}$ body weight sodium heparin.

The left atrial catheter was bisected at the level of the left atrium so that blood could be removed either directly from the left atrium (seven experiments with roller pump and five with vacuum suction) or after it had pooled in the pericardial well (eight experiments with roller pump and 10 with vacuum suction). The suction source was regulated so that all of the blood leaving the left atrial catheter was removed and an equal flow rate of air was also drawn into the system. During both roller pump and vacuum suction the pressure in the suction tube close to the cannula varied from $-4 \mathrm{mmHg}$ at a blood flow rate of 200 $\mathrm{ml} / \mathrm{min}$ to $-10 \mathrm{mmHg}$ at $1000 \mathrm{ml} / \mathrm{min}$. After passing through the cardiotomy reservoir, the blood was $\overline{\bar{c}}$ returned at $37 \cdot 0 \pm 1 \cdot 0^{\circ} \mathrm{C}$ to the animal via the left common femoral artery by another Sarns roller pump. Thus the vacuum suction circuit contained one is roller pump and the roller pump suction circuit $\vec{\circ}$ contained two roller pumps. Blood flow rate was measured by means of a Nycotron extracorporeal $\vec{\omega}$ flow transducer in the arterial line and a Nycotron type 376 blood flowmeter. The flow rate of air was $x$ measured at the cardiotomy reservoir vent by a $\stackrel{\omega}{\oplus}$ calibrated bobbin flowmeter.

Blood and air suction from the left atrium or pericardium and blood reinfusion into the femoral artery $\overrightarrow{0}$ were continued for one hour except in the control group, when they were limited to five minutes to mix $\overrightarrow{0}$ the blood and circuit prime in the same proportions as in the experimental group. After one hour the blood $\frac{0}{0}$ remaining in the cardiotomy reservoir was infused $\stackrel{\mathbb{}}{-}$ into the femoral artery, and the animals were observed $\vec{\varphi}$ under anaesthesia for a further hour.

Throughout the suction and recovery periods. measurements were made of the suction line, cardiotomy reservoir, reinfusion line, and arterial and venous blood pressures using Bell and Howell strain gauge pressure transducers and Devices amplifiers; $\frac{\circ}{\triangleright}$ and of heart rate, oesophageal and blood tempera- $\varrho$ tures, and blood and air flow rates at 15-minute $\overline{0}$ intervals with one additional measurement five minutes after starting suction.

Blood samples were taken from the left atrium and femoral artery for measurements of platelet and $\overrightarrow{\vec{z}}$ leucocyte aggregation by the screen filtration pressure $\frac{0}{\mathrm{~N}}$ (SFP) technique of Swank et al (1964); platelet and $\times$ leucocyte counts by phase contrast microscopy; and $\frac{9}{3}$ packed cell volume, red cell osmotic fragility, whole blood haemoglobin concentration as cyanmethaemo- $\frac{\circ}{3}$ globin, and plasma haemoglobin concentration by the benzidine technique (Crosby and Furth, 1956). Blood smears were stained with Leishman and $\frac{D}{0}$ Giemsa stains.

Data relating to plasma haemoglobin concentra- $\tilde{N}$ tion and to platelet and leucocyte counts were ${ }_{N}$ adjusted to correct for haemodilution, so that all $N$ values are referred to a standard packed cell volume $\omega$ of 0.40 . The traumatic index was calculated as the change in plasma haemoglobin concentration aftero 100 passages of the calculated whole blood volume through the circuit (Koller and Hawrylenko, 1967).

The SFP measurements were corrected for $\frac{0}{7}$ changes in haemodilution by constructing correction $\frac{\vec{D}}{\mathrm{C}}$ graphs based upon serial dilutions of ten blood $\stackrel{\odot}{\square}$ samples with initial SFP values in the range $28-525 \stackrel{\circ}{\circ}$ $\mathrm{mmHg}$ and measuring the SFP at seven different dilutions of each blood sample. The curves were 
found to be linear biphasic with a minimum turning point at $P C V \simeq 0 \cdot 17$. The slope (a) of the phase above $P C V \simeq 0.17$ was linearly related to the initial values of SFP and PCV. Thus:

$$
\begin{gathered}
\text { a } \propto \frac{\text { SFPi }}{\text { PCVi }} \text {, and } \\
\frac{1.4925 \mathrm{SFPi}}{\text { PCVi }}=\frac{\text { dSFP }}{\text { dPCV }}
\end{gathered}
$$

Using this result, the appropriate correction curve was selected according to the value of $\frac{\mathrm{SFPi}}{\mathrm{PCVi}}$ taken from the measurements on the blood sample immediately after the induction of anaesthesia. All SFP measurements were then adjusted to give the SFP corresponding to $\mathrm{PCV}=\mathbf{0 . 4 0}$. This is referred to as

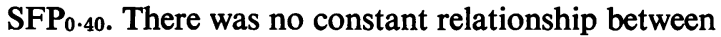
the SFP measurements on serially diluted blood samples and the screen filtration resistance (SFR) value used for a similar purpose by Page et al (1974).

During five preliminary experiments it was found important to wash the pericardial well with $40 \mathrm{ml}$ saline before admitting any blood to the suction system. Failure to do so resulted in immediate massive platelet aggregation, the SFP exceeding the maximum value measurable of $600 \mathrm{mmHg}$ after only five minutes of suction. These experiments were excluded from the series.

The 20 animals that survived until the end of the recovery period were exsanguinated via the right atrium. Tissue samples were taken from the brain, heart, lung, liver, kidney, spleen, and jejunum and immersion-fixed in $2 \%$ phosphate buffered formaldehyde for histology. Sections were stained with haematoxylin and eosin, and with a modified picroMallory stain for platelets (Carstairs, 1965).

Because of the probability that the inclusion of an animal in the circuit could alter the concentrations of cellular aggregates and plasma haemoglobin, 13 additional experiments were performed in vitro. Seven were used to compare roller pump and vacuum suction systems and the other six to examine the effects of aspirating air as well as blood. For these experiments the animals were anaesthetised with Intraval and given $300 \mathrm{IU} / \mathrm{kg}$ body weight of sodium heparin before collecting $500 \mathrm{ml}$ blood from a femoral artery into a sterile empty polyvinyl chloride blood pack.

Two circuits identical to the one used for the invivo experiments were constructed, the position of the animal being occupied by a $500 \mathrm{ml}$ polyvinyl chloride reservoir. Each circuit was primed with 250 $\mathrm{ml}$ heparinised blood, $150 \mathrm{ml}$ Ringer-lactate solution, $5 \mathrm{ml} 8.4 \%$ sodium bicarbonate, and $100 \mathrm{IU} / \mathrm{kg}$ body weight of sodium heparin. Suction was provided as before, and the blood flow rate was maintained for one hour at $450 \mathrm{ml} / \mathrm{min}$, which was the mean flow rate measured during the in-vivo experiments.

Data were analysed for population variance and groups were compared by Student's $t$, MannWhitney $U$, and Wilcoxon rank sum tests as appropriate.

\section{Results}

All six animals in the control group survived until killed, but ten of the 30 animals in the experimental group died before the end of the recovery period. The haematological data from these ten incomplete experiments were not included in the results. The morbid signs were reduced blood flow rate from the left atrium, gradually decreasing arterial blood pressure, and apparently reduced myocardial contractility. Extensive post-mortem and histological examinations showed no indications of the cause of death other than minimal patchy atelectasis of the lungs and a recent adherent thrombus in a small branch of the left coronary artery in one dog. Platelet and leucocyte aggregates were not found, and there were no signs of embolic tissue damage.

Haematological data were analysed by parametric and non-parametric tests. Student's $t$ test for unequal samples and the Mann-Whitney $U$ test were used for in-vivo experiments, and Student's $t$ test for paired data and the Wilcoxon rank sum test for invitro experiments. The conventional $5 \%$ probability criterion was applied in each case.

In the in-vivo experiments the increase in plasma haemoglobin concentration was significantly greater in the suction group composed of all 20 experiments $(17.4 \pm \mathrm{SE} 3.2 \mathrm{mg} / \mathrm{dl})$ than in the control group $(5 \cdot 2 \pm$ SE $2 \cdot 1 \mathrm{mg} / \mathrm{dl})$ (fig 2$)$. The change in platelet

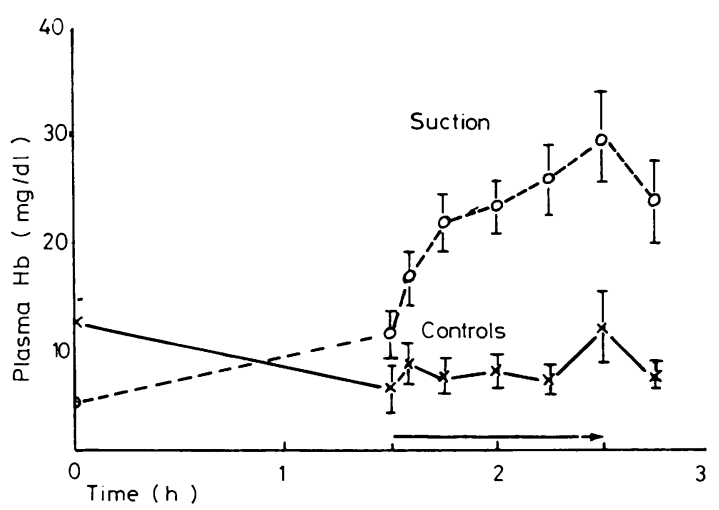

Fig 2 Plasma haemoglobin concentration during in-vivo cardiotomy suction. Arrow indicates suction period. Vertical bars indicate one standard error on each side of mean. 
count was also significantly different in these two groups, decreasing by $23.3 \pm \mathrm{SE} 1.8 \times 10^{9} / 1$ in the suction group and increasing by $61.7 \pm$ SE $49.4 \times$ $10^{9} / 1$ in the control group (fig 3 ). The haematological differences between left atrial and pericardial aspiration and between roller pump and vacuum suction were not significant.

In the in-vitro experiments, however, the increase in plasma haemoglobin concentration was significantly greater in the roller pump group $(2238 \cdot 1 \pm \mathrm{SE}$ $420.3 \mathrm{mg} / \mathrm{dl}$ ) than in the vacuum suction group

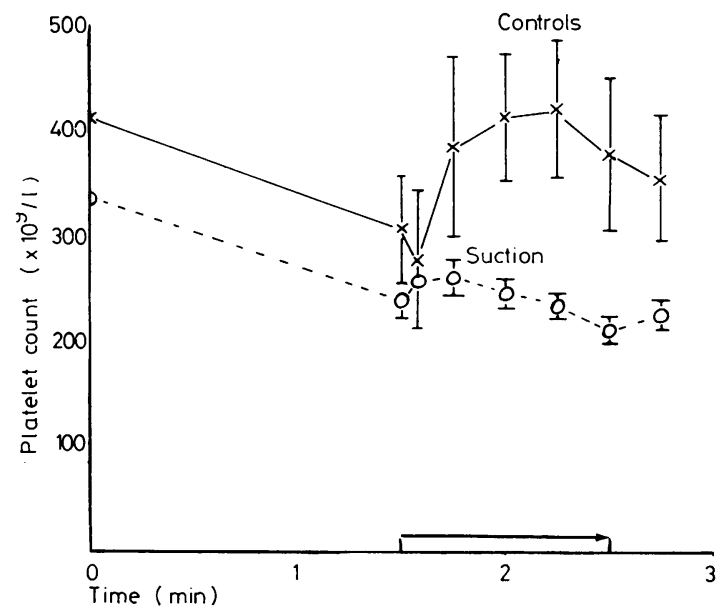

Fig 3 Platelet counts during in-vivo cardiotomy suction. Arrow indicates suction period. Vertical bars represent one standard error on each side of mean, and arrow indicates end of the one-hour suction period.

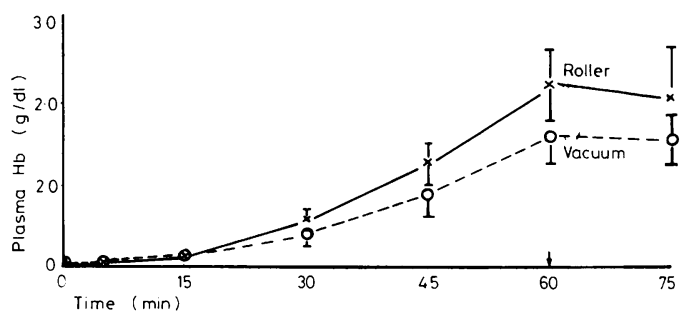

Fig 4 Plasma haemoglobin concentration during in-vitro blood suction using vacuum and roller pumps. Vertical bars represent one standard error on each side of mean, and arrow indicates end of the one-hour suction period.

$(1591.9 \pm$ SE $293.5 \mathrm{mg} / \mathrm{dl}$ ) (fig 4). The most remarkable differences were found in the in-vitro experiments performed to examine the effects of air aspiration (table, figs 5-7). Each pair of values is significantly different at the $5 \%$ probability level.

Haematological changes during one-hour of suction and recirculation of dog blood. Each value shown is mean and standard error

\begin{tabular}{lcc}
\hline & \multicolumn{2}{l}{ Fluid aspirated } \\
\cline { 2 - 3 } & Blood and air & Blood alone \\
\hline $\begin{array}{c}\Delta \text { plasma haemoglobin } \\
\text { concentration (mg/dl) }\end{array}$ & $2167.9 \pm 323.0$ & $214.6 \pm 121.9$ \\
$\begin{array}{c}\Delta \text { screen filtration pressure } \\
\text { (SFP 0.40) (mmHg) }\end{array}$ & $39.2 \pm 11.2$ & $-2.3 \pm 0.8$ \\
$\begin{array}{c}\Delta \text { packed cell volume } \\
\text { pplatelet count }\left(\times 10^{\circ} / \mathrm{l}\right)\end{array}$ & $-264.7 \pm 16.6$ & $-100.5 \pm 0.0$ \\
\hline
\end{tabular}

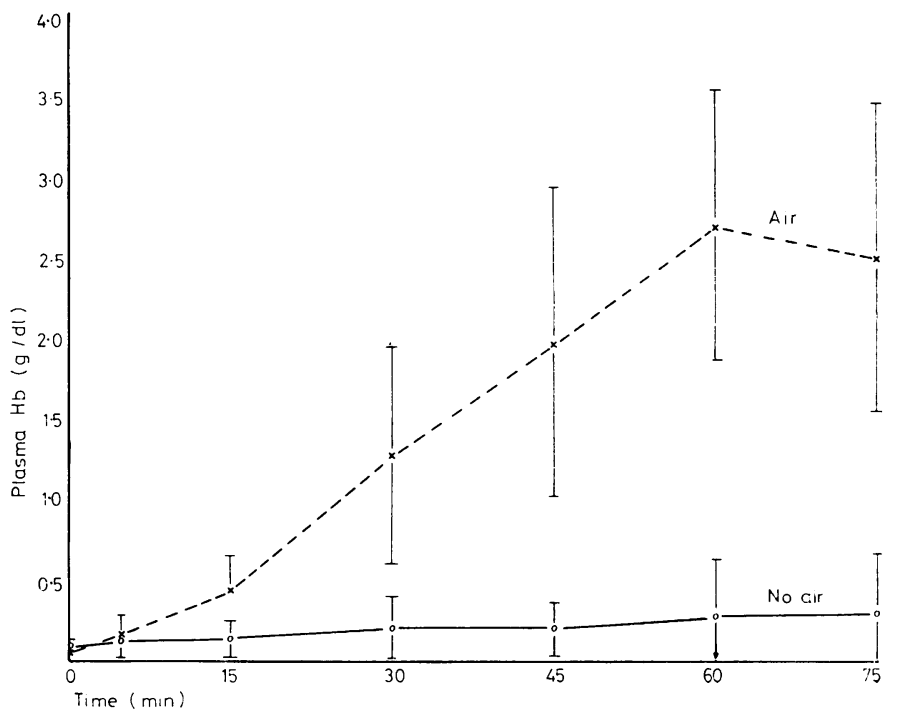

Fig 5 Plasma haemoglobin concentration during in-vitro suction of blood and air and of blood alone. Vertical bars represent one standard error on each side of mean, and arrow indicates end of one-hour suction period. 

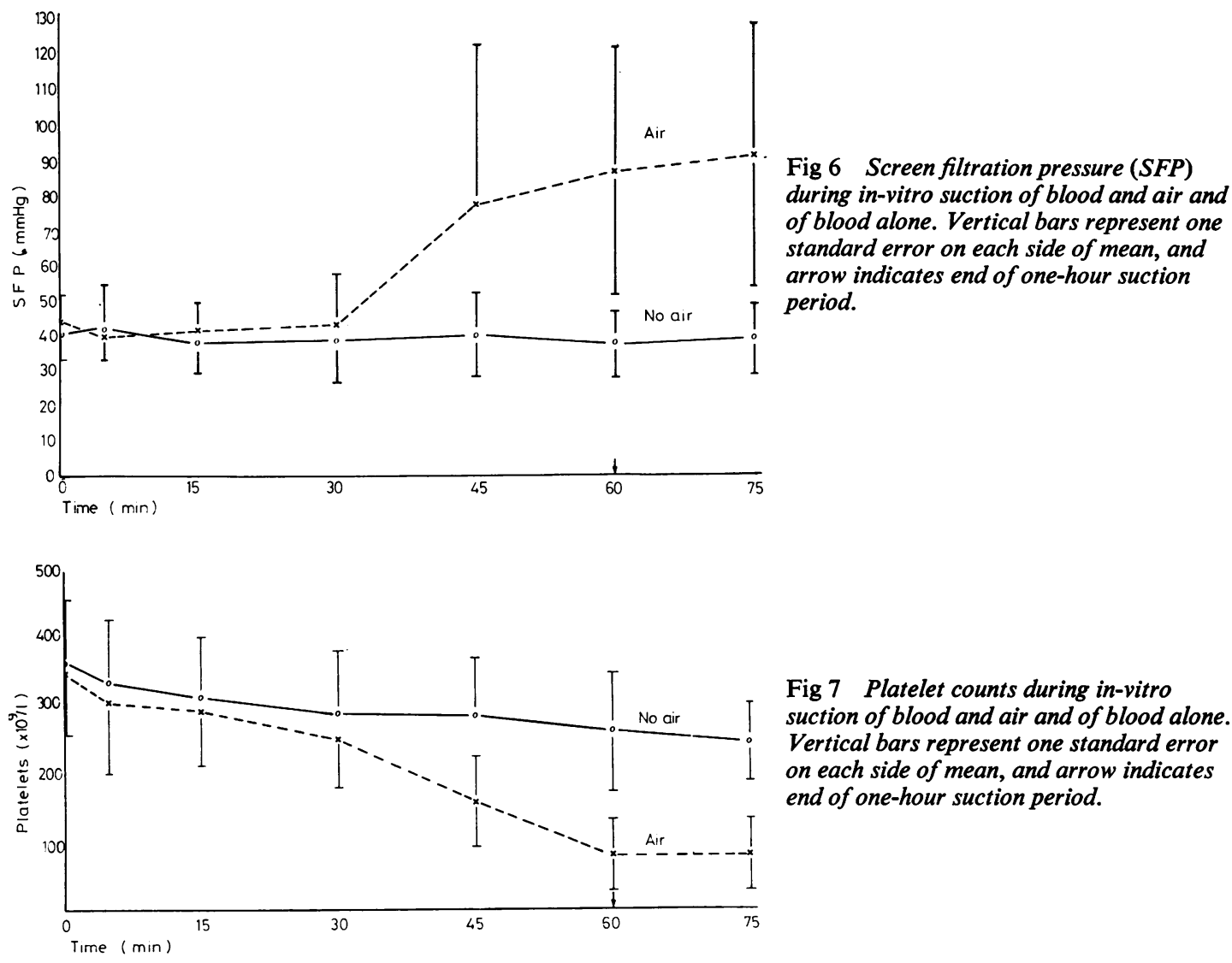

Fig 7 Platelet counts during in-vitro suction of blood and air and of blood alone. Vertical bars represent one standard error on each side of mean, and arrow indicates end of one-hour suction period.

\section{Discussion}

The principal conclusion to be drawn from these experiments is that cardiotomy suction of an air/ blood mixture can be responsible for considerable cell destruction and platelet aggregation. This has been supported by measurements made on human blood samples taken from the oxygenator and cardiotomy reservoir during two open heart operations. The final plasma haemoglobin concentrations were 18.6 and $63.6 \mathrm{mg} / \mathrm{dl}$ in the oxygenators and 156.6 and $213.9 \mathrm{mg} / \mathrm{dl}$ in the cardiotomy reservoirs. The most likely causes of the cell changes in the suction system are the mechanical forces acting at the suction cannula. Direct observations and photography showed that blood and air flowed down the suction tube to the reservoir in short boluses with more or less parabolic velocity profiles. It was not possible to determine whether the flow was laminar within the boluses, but the fully developed flow pattern was established about $10 \mathrm{~cm}$ from the inlet with blood and air each being moved at $450 \mathrm{ml} / \mathrm{min}$ (total flow rate $900 \mathrm{ml} / \mathrm{min}$ ). For laminar flow from a stationary reservoir, the inlet length is calculated to be $26 \cdot 7 \mathrm{~cm}$.

$$
\begin{aligned}
& \mathrm{X}=0.08 \mathrm{r} \frac{(\mathrm{Ud})}{\mathrm{V}}, \mathrm{X}=\text { inlet length } \\
& \mathrm{U}=\text { average velocity } \\
& \mathrm{d}=\text { tube diameter (McDonald, } \\
& \text { 1974) } \\
& \mathrm{V}=\text { kinematic viscosity }
\end{aligned}
$$

(The inlet length is the distance from the inlet orifice at which the flow pattern becomes fully formed.)

For laminar flow from a turbulent reservoir, the inlet length is only $1.77 \mathrm{~cm}$.

$$
X=1 \cdot 386 r \frac{(U d)^{t}}{V} \text {. }
$$

If the flow pattern through the inlet cannula was laminar and parabolic the wall shear stress would be

$$
\tau_{\mathrm{L}}=\mu \frac{\mathrm{dv}}{\mathrm{dr}} \quad \begin{aligned}
\tau_{\mathrm{L}} & =\text { laminar shear stress } \\
\mu & =\text { absolute viscosity } \\
\mathrm{v} & =\text { velocity } \\
\mathrm{r} & =\text { tube radius }
\end{aligned}
$$


Figure 8 shows the relationship between blood flow rate and maximum shear stress for cannulae of $1 \mathrm{~mm}$ to $9 \mathrm{~mm}$ id up to the critical Reynold's number of 2300 $\left(\operatorname{Re}=\frac{\mathrm{Ud}}{\mathrm{v}}\right)$. At flow rates above the values corresponding to a transitional region of $\operatorname{Re}=2300$ to 2500 , the flow becomes turbulent, and the shear stresses are much higher.

Using the Poiseuille relationship, the predicted pressure drop along the cannula would be much less than $1 \mathrm{mmHg}$ at $450 \mathrm{ml} / \mathrm{min}$. The measured pressure drop was $4 \mathrm{mmHg}$. This lack of correspondence is probably because the inlet region is relatively large. The pressure drop was linearly related to blood flow rate up to $750 \mathrm{ml} / \mathrm{min}$, at which there was a turning point and a steeper linear relation beyond. This may indicate a laminar flow up to $750 \mathrm{ml} / \mathrm{min}$ and turbulence at higher flow rates.

The relation between pressure drop and flow rate for an equal-parts mixture of blood and air was parabolic and the pressure drops were relatively higher than for blood alone (about double at a blood flow rate of $750 \mathrm{ml} / \mathrm{min}$ ). This additional pressure drop does not appear to be due to the additional energy required to move the air because the viscosity

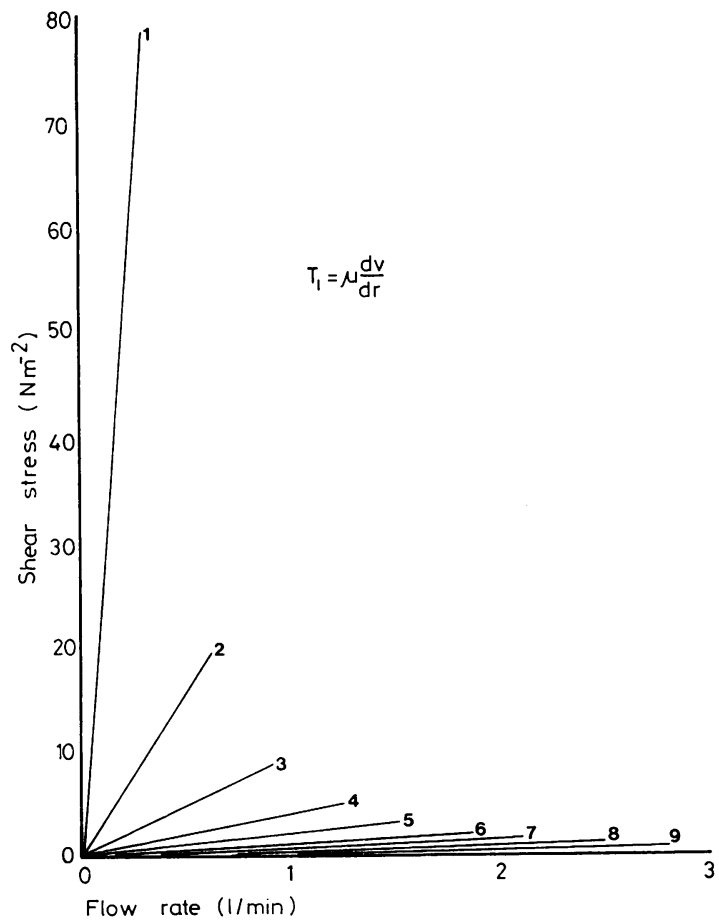

Fig 8 Laminar shear stresses calculated for whole blood flowing through tubes 1-9 mm internal diameter. Each line terminates at critical Reynold's number $(\operatorname{Re}=2300)$. of air is so low $\left(190.4 \mu \mathrm{P}\right.$ at $\left.40^{\circ} \mathrm{C}\right)$ (Weast, 1974). An alternative explanation is that the additional pressure dissipation is from local or general turbulence within the bulk flow. This would generate high local shear stresses, which could be responsible for the high rates of blood trauma during blood and air aspiration.

Schlichting (1960) has proposed the following formula to describe the stress-strain relation in fully formed turbulent flows.

$$
\begin{aligned}
\tau_{\mathrm{t}}=\mathrm{e} \epsilon \frac{\mathrm{dv}}{\mathrm{dr}}=0.03 \frac{2 \Delta \mathrm{P}}{\mathrm{e}}, \text { where } \tau \mathrm{t} & =\text { turbulent shear stress } \\
\mathrm{e} & =\text { density } \\
\epsilon & =\text { eddy current kine- } \\
\Delta \mathrm{P} & =\text { matic viscosity } \\
& \text { pressure drop }
\end{aligned}
$$

Using this formula, the measured blood trauma can be explained as the result of turbulent shear stresses. Figure 9 shows the shear stress-flow rate relation for turbulent flows calculated by Schlichting's formula using the measured pressure drop along the suction cannula. The vertical broken line indicates the shear stresses corresponding to the blood flow rate used in the in-vitro experiments. The immediate cellular effects of imposed shear stresses were reported by Nevaril et al (1968), Goldsmith (1974), and Hung et al (1976). Cell trauma increases with the duration of imposition of shear stress at least for short periods (Colantuoni et al, 1977). Probably therefore, exposure to a shear stress of about $140 \mathrm{~N} \mathrm{~m}^{-2}$ could cause severe cell trauma, especially when wall impact effects are included since these can be considerable (Johnston et al, 1975).

Thus the greatly increased levels of cell trauma during blood and air aspiration may be explained by the much higher shear stresses resulting from turbulent flow conditions. The benefits to be derived by reducing the blood flow rate, increasing the diameter of the suction cannula, and avoiding air aspiration are apparent.

The stress-strain model for turbulent flows suffers $\stackrel{\bigcirc}{\frac{1}{2}}$ from the limitation that it is not known whether $\frac{D}{2}$ Schlichting's formula can be applied to fluid mixtures and to the two limitations mentioned above, that is, No no account is taken of time-dependent and wallimpact effects. Actually these factors would be likely 0 to increase the differences between laminar and $\omega$ turbulent shear effects. Furthermore, the appropriate values of $e$ and $\epsilon$ are unknown. (In the construction $\varphi$ of figure 9 , e has been calculated as $\frac{1 \cdot 05 \times 1 \cdot 12+10^{-3}}{2}$.) $\stackrel{\oplus}{\stackrel{?}{?}}$ Finally, the exceptionally high $\left(10^{4} \mathrm{~N} \mathrm{~m}^{-2}\right)$ threshold $\frac{7}{0}$ for cell deformation found by Bernstein et al (1977) $\underset{\mathbb{D}}{\stackrel{D}{*}}$ and the exceptionally low value of $10 \mathrm{~N} \mathrm{~m}^{-2}$ required $\stackrel{\rho}{\oplus}$ for platelet aggregation reported by Brown et al (1975) $\cong$ have not been included. We are left with the conclusion that the shear stress model of cardiotomy 


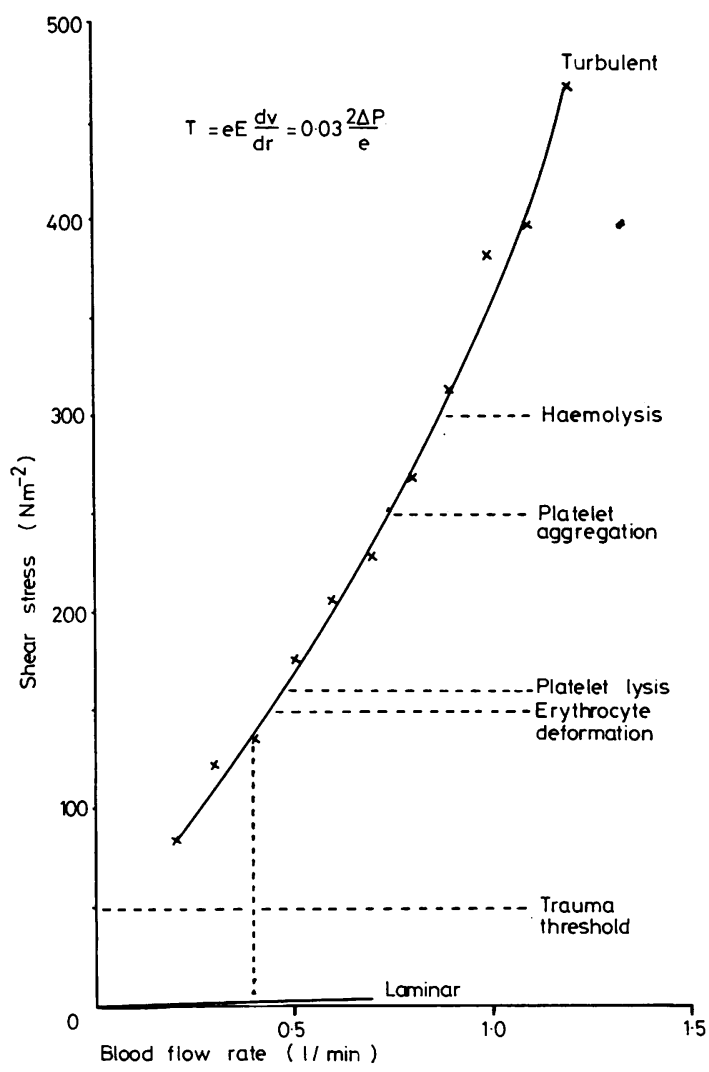

Fig 9 Laminar and turbulent shear stresses for blood and air flowing through tubes of $4 \mathrm{~mm}$ internal diameter.

suction is capable of predicting results that agree well with the measured cell trauma, but that in view of the analytical limitations and the variation in the reported data on the cellular effects of shear stress, it must be regarded as a qualitative guide. It should not be used to make quantitative predictions in its present form. Thus in a qualitative way it could be used to explain the high levels of cell trauma during blood circulation and oxygenation as due to local turbulent shear stresses in the bubble oxygenator (Wright and Sanderson, 1976).

Based on this discussion, the general conclusions are that vacuum suction will cause less cell trauma than roller pump suction, and that cell trauma can be dramatically reduced by the avoidance of air aspiration. The problem of air aspiration may be overcome by the use of a controlled suction system such as those developed by Barthelemy et al (1978) and by ten Duis et al (1978).

In conclusion, we should mention that we did not encounter the massive haemolysis of blood caused by contact with the pericardium reported by Morris et al (1965) and by Wells et al (1968). We did, however, measure severe immediate platelet aggregation during five preliminary experiments. This was avoided in the subsequent experiments by washing the pericardium and epicardium with saline before allowing blood to enter the suction system. This point deserves further investigation.

Technical advice given by Dr $\mathrm{K} \mathrm{H}$ Parker of the Imperial College of Science and Technology and the assistance of Mrs Margaret Riley are acknowledged. Most of the work was performed with the aid of a grant from the British Heart Foundation.

\section{References}

Barthelemy, R, Vives, M, Couzy, H, Morucci, J P, Puel, $P$, and Enjalbert, A (1978). Dispositif de controle automatique des aspirations chirurgicales en chirurgie cardiaque. Medical and Biological Engineering and Computing, 16, 165-168.

Bernstein, E F, Marzec, U, and Johnston, G G (1977). Structural correlates of platelet functional damage by physical forces. Transactions of the American Society for Artificial Internal Organs, 23, 617-625.

Brown, C H, Lemuth, R F, Hellums, J D, Leverett, L B, and Alfrey, C P (1975). Response of human platelets to shear stress. Transactions of the American Society for Artificial Internal Organs, 21, 35-38.

Caguin, F, and Carter, M G (1963). Fat embolization with cardiotomy with the use of cardiopulmonary bypass. Journal of Thoracic and Cardiovascular Surgery, 46, 665-672.

Colantuoni, G, Hellums, J D, Moake, J L, and Alfrey, C P (1977). The response of human platelets to shear stress at short exposure time. Transactions of the American Society for Artificial Internal Organs, 23, 626-631.

Carstairs, K C (1965). The identification of platelets and platelet antigens in histological sections. Journal of Pathology and Bacteriology, 90, 225-231.

Crosby, W H, and Furth, F W (1956). A modification of the benzidine method for measurement of hemoglobin in plasma and urine. Blood, 11, 380-383.

Evans, E A, and Wellington, J S (1964). Emboli associated with cardiopulmonary bypass. Journal of Thoracic and Cardiovascular Surgery, 48, 323-330.

Furness, A (1977). Microbubble detection during extracorporeal circulation for open heart surgery. PhD thesis, University of Keele, England.

Goldsmith, H L (1974). The effects of flow and fluid mechanical stress on red cells and platelets. Transactions of the American Society for Artificial Internal Organs, 20, 21-26.

Hill, J D, Osborn, J J, Swank, R L, Aguilar, M J, de Lanerolle, P, and Gerbode, F (1970). Experience using a new Dacron wool filter during extracorporeal circulation. Archives of Surgery, 101, 649-652.

Hung, T C, Hochmuth, R M, Joist, J H, and Sutera, S P (1976). Shear-induced aggregation and lysis of platelets. 
Transactions of the American Society for Artificial Internal Organs, 22, 285-291.

Johnston, G G, Marzec, U, and Bernstein, E F (1975). Effects of surface injury and shear stress on platelet aggregation and serotonin release. Transactions of the American Society for Artificial Internal Organs, 21, 413-421.

Katsumoto, K, Watanabe, S, and Tanaka, S (1973). Evaluation of micropore filter in the extracorporeal circulation. Japanese Circulation Journal, 37, 785-796.

Koller, T, and Hawrylenko, A (1967). Contribution to the in vitro testing of pumps for extracorporeal circulation. Journal of Thoracic and Cardiovascular Surgery, 54, 22-29.

Loop, F D, Szabo, J, Rowlinson, R D, and Urbanek, P E (1976). Events related to microembolism during extracorporeal perfusion in man: Effectiveness of in-line filtration recorded by ultrasound. Annals of Thoracic Surgery, 21, 412-420.

McDonald, D A (1974). Blood Flow in Arteries, 2nd edn. Edward Arnold, London.

Morris, K N, Kinross, F M, and Stirling, G R (1965). Hemolysis of blood in the pericardium: The major source of plasma hemoglobin during total body perfusion. Journal of Thoracic and Cardiovascular Surgery, 49, 250-258.

Nevaril, C G, Lynch, E C, Alfrey, C P, and Hellums, J D (1968). Erythrocyte damage and destruction induced by shearing stress. Journal of Laboratory and Clinical Medicine, 71, 784-790.

Osborn, J J, Swank, R L, Hill, J D, Aguilar, M J, and Gerbode, F (1970). Clinical use of a Dracon wool filter during perfusion for open-heart surgery. Journal of Thoracic and Cardiovascular Surgery, 60, 575-581.

Page, U S, Bigelow, J C, Carter, C R, and Swank, R L (1974). Emboli (debris) produced by bubble oxygenators. Removal by filtration. Annals of Thoracic Surgery, 18, 164-171.

Rygg, I H (1973). Studies in Extracorporeal Circulation. The Design and Development of a Heart-lung Machine. F A D L, Copenhagen.

Schlichting, H (1960). Boundary Layer Theory, 4th edn. McGraw-Hill, New York.

Skagseth, E, Froysaker, T, Refsum, S B (1974). Disposable filter for microemboli in cardiopulmonary bypass.
Clinical and histological findings. Journal of Cardiovascular Surgery, 15, 318-322.

Solis, R T, Noon, G P, Beall, A C, and DeBakey, M E (1974). Particulate microembolism during cardiac operation. Annals of Thoracic Surgery, 17, 332-344.

Solis, R T, Kennedy, P S, Beall, A C, Noon, G P, and DeBakey, M E (1975). Cardiopulmonary bypass. Microembolization and platelet aggregation. Circulation, 52, 103-108.

Swank, R L, Roth, J G, and Jansen, J (1964). Screen filtration pressure method and adhesiveness and aggregation of blood cells. Journal of Applied Physiology, 19, 340-346.

ten Duis, H J, de Jong, J C F, van Asseldonk, A G M, Smit Sibinga, C T, and Wildevuur, C R H (1978). Improved hemocompatibility in open heart surgery. Transactions of the American Society for Artificial Internal Organs, 24, 656-661.

Weast, R C (ed) (1974). Handbook of Chemistry and Physics, 55th edn. CRC Press, Cleveland, Ohio.

Wells, R, Bygdeman, M S, Shahriari, A A, and Matloff, J M (1968). Influence of a defoaming agent upon the hematological complications of pump oxygenators. Circulation, 37, 638-647.

Wielogorski, J W, Cross, D E, and Nwadike, E V O (1975). The effects of subatmospheric pressure on the haemolysis of blood. Journal of Biomechanics, 8, 321-325.

Wright, E S, Sarkozy, E, Dobell, A R C, and Murphy, D R (1963). Fat globulemia in extracorporeal circulation. Surgery, 53, 500-504.

Wright, G (1976). L'aggrégation cellulaire au cours d'une circulation extra-corporelle. Les cahiers $d u$ Cercle d'Étude de la Circulation Extra-corporelle, 6, 27-37.

Wright, $G$ (1977). The avoidance of blood cell aggregation during extracorporeal circulation for open-heart surgery. Proceedings of the European Society for Artificial Organs, 3, 102-105.

Wright, G, and Sanderson, J M (1976). Cellular aggregation and destruction during blood circulation and oxygenation. Thorax, 31, 405-409.

Requests for reprints to: Dr G Wright, Department of Biological Sciences, University of Keele, Keele, Staffs ST5 5BG. 